\title{
Kinetic studies of the reaction $\mathrm{NH}_{2}+\mathrm{H}_{2} \mathrm{~S}$
}

\author{
Yide Gao, Paul Marshall* \\ Department of Chemistry and Center for Advanced Scientific Computing and Modeling, University of North Texas, 1155 Union Circle \#305070, Denton, TX 76203-5017, USA
}

\section{A R T I C L E I N F O}

\section{Article history:}

Received 3 January 2014

In final form 9 January 2014

Available online 21 January 2014

\begin{abstract}
A B S T R A C T
Amidogen $\left(\mathrm{NH}_{2}\right)$ radicals were generated by pulsed laser photolysis of ammonia precursor at $193 \mathrm{~nm}$, and monitored by laser-induced fluorescence excited at $570.3 \mathrm{~nm}$. Experiments were conducted in argon bath gas with traces of hydrogen sulfide $\left(\mathrm{H}_{2} \mathrm{~S}\right)$ at pressures of 9-25 mbar and temperatures of 294-820 K. The $\mathrm{NH}_{2}+\mathrm{H}_{2} \mathrm{~S}$ rate constant was found to be $(4.30 \pm 0.25) \times 10^{-13} \mathrm{~cm}^{3}$ molecule $\mathrm{s}^{-1}$ independent of temperature. The rate constant for removal of vibrationally-excited $\mathrm{NH}_{2}(0,1,0)$ by $\mathrm{H}_{2} \mathrm{~S}$ was estimated as $(1.5 \pm 0.2) \times 10^{-11} \mathrm{~cm}^{3}$ molecule $\mathrm{s}^{-1}$, which includes both physical quenching and chemical reaction.
\end{abstract}

(C) 2014 Elsevier B.V. All rights reserved.

\section{Introduction}

There have been no prior studies of the system:

$\mathrm{NH}_{2}+\mathrm{H}_{2} \mathrm{~S} \rightarrow$ products

Here we present results obtained over $295-820 \mathrm{~K}$ obtained via the laser pulsed photolysis/laser-induced fluorescence (LIF) technique, and briefly interpret them in the context of a computed potential energy diagram. One motivation for the present letter is that coupling between sulfur and nitrogen chemistry appears to influence formation of nitrogen oxides in sulfur-doped flames, but the mechanism is unclear [1,2]. Reaction (1) might couple $S$ and $\mathrm{N}$-species under reducing conditions. Another motivation arises from consideration of the reaction of isoelectronic $\mathrm{OH}$ with $\mathrm{H}_{2} \mathrm{~S}$ :

$\mathrm{OH}+\mathrm{H}_{2} \mathrm{~S} \rightarrow \mathrm{H}_{2} \mathrm{O}+\mathrm{SH}$

which exhibits an intriguing temperature dependence. Measurements of $k_{2}$ made at moderate temperatures yielded a zero or negative activation energy, which became significantly positive at higher temperatures. This behavior has been rationalized theoretically in terms of a reaction coordinate involving a bound intermediate [3]. An aim of the present letter is to see whether similar behavior is observed for reaction (1). As a surrogate for the encounter rate between $\mathrm{NH}_{2}$ and $\mathrm{H}_{2} \mathrm{~S}$, we measure the removal rate of vibrationally-excited $\mathrm{NH}_{2}$. Smith has proposed that, if an initially formed excited intermediate is sufficiently bound, it may have sufficient lifetime for excess vibrational energy in the reactants to be lost via intramolecular vibrational relaxation (IVR) [4]. Under these circumstances the rate of loss of $\mathrm{NH}_{2}(v=1)$ might be expected to be

\footnotetext{
* Corresponding author.

E-mail address: marshall@unt.edu (P. Marshall).
}

similar to the initial capture rate of $\mathrm{NH}_{2}$ by $\mathrm{H}_{2} \mathrm{~S}$, even if the adduct is not collisionally stabilized.

\section{Methodology}

The reaction cell and general operating procedures have been detailed previously [5,6], while the LIF system is new. Following their generation by $193 \mathrm{~nm}$ pulsed laser photolysis of $\mathrm{NH}_{3}, \mathrm{NH}_{2}$ radicals react with a large excess of $\mathrm{H}_{2} \mathrm{~S}$ diluted in Ar bath gas. The hydrogen sulfide ( $99.5 \%$ grade from MG Industries) was purified first by trapping at $77 \mathrm{~K}$ and degassing, which was repeated for several 'freeze-pump-thaw' cycles. The $\mathrm{H}_{2} \mathrm{~S}$ was then distilled repeatedly from $210 \mathrm{~K}$ (chloroform slush) and trapped at $77 \mathrm{~K}$. Ammonia (MG Industries, 99.99\%) was trapped and degassed at 77 K. Argon was used directly from the cylinder $(99.995 \%$, Air Liquide and Big Three). Gas mixtures were prepared manometrically in glass bulbs.

Under pseudo-first-order conditions we may write:

$\mathrm{d}\left[\mathrm{NH}_{2}\right] / \mathrm{d} t=-\left(k_{1}\left[\mathrm{H}_{2} \mathrm{~S}\right]+k^{\prime}\right)\left[\mathrm{NH}_{2}\right]=-k_{\mathrm{ps} 1}\left[\mathrm{NH}_{2}\right]$

where $k^{\prime}$ mainly accounts for diffusional loss of $\mathrm{NH}_{2}$ out of the reaction zone, which is defined by the intersection of the photolysis and probe laser beams. Ground state $\mathrm{X}^{2} \mathrm{~B}_{1} \mathrm{NH}_{2}$ radicals were electronically excited to the $\mathrm{A}^{2} \mathrm{~A}_{1}$ state by a dye laser (Spectra-Physics, Quanta-Ray PDL-2E) pumped by a Nd:YAG laser (Spectra-Physics, Quanta-Ray INDI, with a repetition rate of $10 \mathrm{~Hz}$ ) at $570.3 \mathrm{~nm}$, which corresponds to absorption in the $2_{12}-2_{02}$ rotational transition of the $(0,10,0) \leftarrow(0,0,0)$ vibronic band [7]. In some experiments vibrationally-excited $\mathrm{NH}_{2}$ was detected via LIF excitation at $531.8 \mathrm{~nm}$ which corresponds to the $2_{1}^{6}(0,13,0) \leftarrow(0,1,0)$ transition [8]. The fluorescence signal passed through a cut-off filter which transmitted wavelengths longer than $590 \mathrm{~nm}$ (OG590, Edmund Optics) and was detected by a photomultiplier tube 
(PMT, Electron Tubes, 9816B). The PMT output was amplified (Electron Tubes C632), and then recorded by a digital storage oscilloscope (BK Precision, model 2542). The time delay between the photolysis and probe laser pulses was controlled with a digital delay/pulse generator (Stanford Research Systems, model DG535). Above $650 \mathrm{~K}$ significant black body radiation interfered with detection and a bandpass filter (Oriel, model 53915, $10 \mathrm{~nm}$ fwhm centered at $590 \mathrm{~nm}$ ) was used to block some of this radiation, allowing temperatures as high as $800 \mathrm{~K}$ to be reached.

The LIF signals captured in the digital storage oscilloscope were transferred to a computer for integration. This integrated signal is expected to be proportional to $\left[\mathrm{NH}_{2}\right]$, and so is expected to vary as an exponential decay according to the form of Eq. (4), plus a constant background arising from scattered light. An example is shown in Figure 1. Initial radical concentrations were estimated from the UV absorption cross sections of $\mathrm{H}_{2} \mathrm{~S}$ and $\mathrm{NH}_{3}$, and the temperature in the reaction zone was monitored before and after experiments with a thermocouple and corrected for radiation errors [9]. Figure 2 is a plot of $k_{\mathrm{ps} 1}$ vs. reactant concentration, whose slope equals the bimolecular rate constant $k_{1}$. The intercept corresponds to $k^{\prime}$ and is small, so that the loss of $\mathrm{NH}_{2}$ is dominated by reaction (1).

\section{Results}

Table 1 summarizes the experimental conditions for 12 determinations of $k_{1}$ for ground-state $\mathrm{NH}_{2}$ over $294-820 \mathrm{~K}$, and 5 measurements for $\mathrm{NH}_{2}$ in the $v=1$ state. $\tau_{\text {res }}$ is the average residence time of gas in the reactor before photolysis, $F$ is the photolysis pulse energy (beam cross section $1.0 \mathrm{~cm}^{2}$ ), and $P$ is the total pressure, mainly Ar bath gas. For each determination typically 10 values of $\left[\mathrm{H}_{2} \mathrm{~S}\right]$ were employed, and the highest value is listed. The corresponding maximum initial [SH], arising from photolysis of $\mathrm{H}_{2} \mathrm{~S}$, is also listed. Similarly, the fixed $\left[\mathrm{NH}_{3}\right]$ and corresponding initial $\left[\mathrm{NH}_{2}\right]$ are given. It may be seen that $k_{1}$ is independent, within its statistical variation (derived from the slopes of plots like Figure 2 ), from $F$ and the initial radical concentrations, which suggests that reaction (1) has been successfully isolated from secondary chemistry. Also, $\left[\mathrm{NH}_{2}\right] \ll\left[\mathrm{H}_{2} \mathrm{~S}\right]$, confirming that pseudo-first-order conditions applied. $k_{1}$ shows no clear variation with temperature and we report the weighted mean over $294-820 \mathrm{~K}$ as $4.30 \times 10^{-13} \mathrm{~cm}^{3}$ molecule $\mathrm{e}^{-1} \mathrm{~s}^{-1}$ with a purely statistical standard deviation of $0.06 \times 10^{-13} \mathrm{~cm}^{3}$ molecule ${ }^{-1} \mathrm{~s}^{-1}$. With an allowance of $5 \%$ for systematic instrumental errors, we estimate $95 \%$ confidence limits of $\pm 0.25 \times 10^{-13} \mathrm{~cm}^{3}$ molecule $\mathrm{e}^{-1} \mathrm{~s}^{-1}$. The removal rate constant for $\mathrm{NH}_{2}(0,1,0)$ can be approximately represented

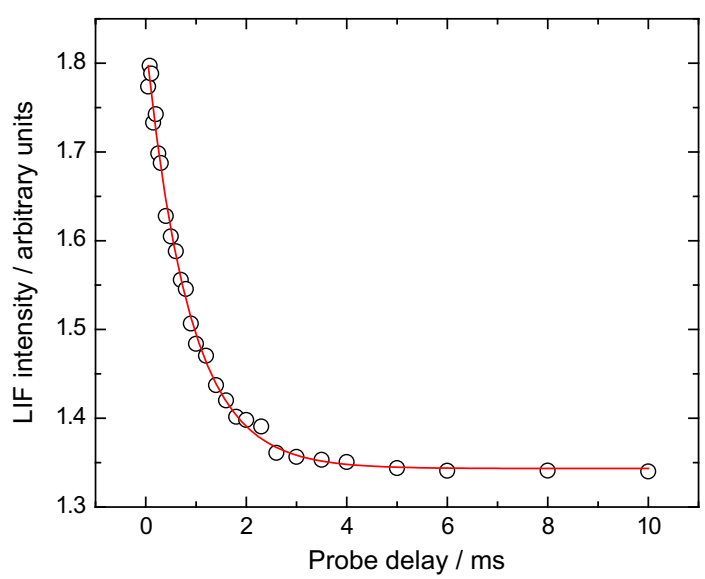

Figure 1. Example of the LIF signal for $\mathrm{NH}_{2} \mathrm{X}(0,0,0)$ in the presence of $\mathrm{H}_{2} \mathrm{~S}$ as a function of the delay time between the photolysis and probe lasers together with an exponential fit to the decay.

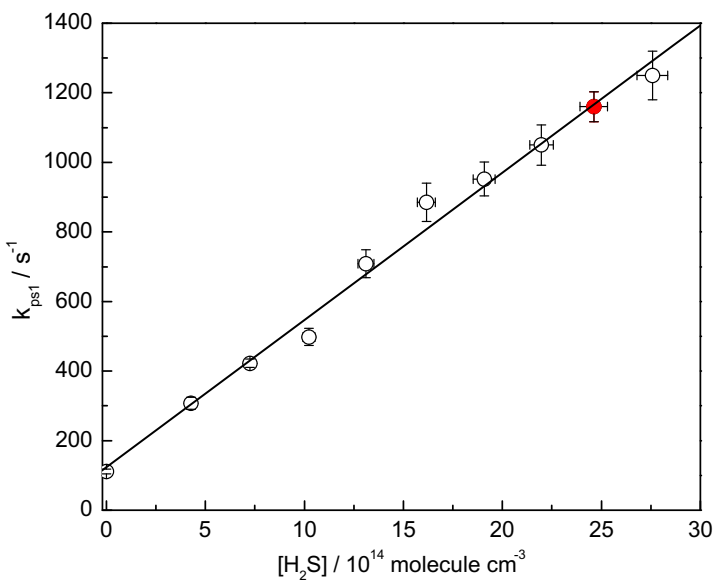

Figure 2. Variation of the pseudo-first-order rate coefficients for the removal of $\mathrm{NH}_{2} \mathrm{X}(0,0,0)$ with the concentration of $\mathrm{H}_{2} \mathrm{~S}$ at $T=295 \mathrm{~K}, P=28 \mathrm{mbar}$, and a photolysis laser energy of $0.4 \mathrm{~mJ}$. The error bars represent $\pm 1 \sigma$ in concentration and decay rate and the filled point corresponds to the decay shown in Figure 1.

as $(1.5 \pm 0.2) \times 10^{-11} \mathrm{~cm}^{3}$ molecule ${ }^{-1} \mathrm{~s}^{-1}$, which includes both physical quenching and chemical reaction.

\section{Discussion}

There are no prior measurements of $k_{1}$ for comparison. According to a recent review, the isoelectronic process 2 is an order of magnitude faster at room temperature and exhibits a very small positive activation energy of $0.6 \mathrm{~kJ} \mathrm{~mol}^{-1}$ [10]. The temperature dependence is therefore similar to that for reaction (1). We have investigated the $\mathrm{NH}_{2}+\mathrm{H}_{2} \mathrm{~S}$ potential energy surface using the W1Usc approach of Martin and coworkers [11] implemented in the Gaussian09 program suite [12]. Geometries and frequencies (scaled by 0.985 ) of stationary points were derived at the B3LYP/ $c c-p V(T+d) Z$ level of density functional theory, followed by several steps which combine to approximate the coupled cluster $\operatorname{CCSD}(\mathrm{T})$ energy at the infinite basis set limit, with all electrons correlated and corrected for scalar relativistic effects at the DKH level.

Because of the observed effectively zero activation energy for reaction (1), our focus is on product channels which are exothermic or only slightly endothermic. The obvious choice is:

$\mathrm{NH}_{2}+\mathrm{H}_{2} \mathrm{~S} \rightarrow \mathrm{NH}_{3}+\mathrm{SH}$

for which the W1Usc reaction enthalpy at $0 \mathrm{~K}$ is $\Delta_{r} H_{0}=-65.8 \mathrm{~kJ} \mathrm{~mol}^{-1}$. Correction for the spin-orbit splitting in $\mathrm{SH}$ yields $\Delta_{r} H_{0}=-68.1 \mathrm{~kJ} \mathrm{~mol}^{-1}$, which compares well with the experimental value of $-67.3 \mathrm{~kJ} \mathrm{~mol}^{-1}[13,14]$. This is consistent with the root-mean-square deviation of $2.4 \mathrm{~kJ} \mathrm{~mol}^{-1}$ for application of W1Usc theory to a test set of divers energies [11]. The only other $\mathrm{NSH}_{4}$ combination lower in energy than the reactants is:

$\mathrm{NH}_{2}+\mathrm{H}_{2} \mathrm{~S} \rightarrow \mathrm{H}_{2} \mathrm{NS}+\mathrm{H}_{2}$

for which the computed $\Delta_{r} H_{0}$ is $-32.8 \mathrm{~kJ} \mathrm{~mol}^{-1}$. The enthalpy of formation of $\mathrm{H}_{2} \mathrm{NS}$ appears to be unknown; our result implies $\Delta_{f-}$ $H_{0}=138.5 \mathrm{~kJ} \mathrm{~mol}^{-1}$. The isomers $\mathrm{HNSH}$ and $\mathrm{NSH}_{2}$ are higher in enthalpy by 62 and $266 \mathrm{~kJ} \mathrm{~mol}^{-1}$, respectively, and are not plausible candidates. Formation of $\mathrm{H}+$ trans $-\mathrm{H}_{2} \mathrm{NSH}$, the most stable $\mathrm{NSH}_{3}$ isomer [15], is endothermic by $104 \mathrm{~kJ} \mathrm{~mol}^{-1}$ so these isomers are not considered further.

The corresponding reaction pathways are plotted in Figure 3. For reaction (1b) there is a direct transition state (TS) which is drawn in Figure 4. However, its energy is $187 \mathrm{~kJ} \mathrm{~mol}^{-1}$ above the reactants so this cannot be a significant channel under our conditions. Pathway 1a has a weakly bound complex in the entrance 
Table 1

Summary of measurements of the rate constant $k_{1}$ for $\mathrm{H}_{2} \mathrm{~S}+\mathrm{NH}_{2}(v=0$ and $v=1)$.

\begin{tabular}{|c|c|c|c|c|c|c|c|c|}
\hline $\begin{array}{l}T \\
(\mathrm{~K})\end{array}$ & $\begin{array}{l}\tau_{\text {res }} \\
(s)\end{array}$ & $\begin{array}{l}F \\
(\mathrm{~mJ})\end{array}$ & $\begin{array}{l}P \\
\text { (mbar) }\end{array}$ & $\begin{array}{l}{\left[\mathrm{H}_{2} \mathrm{~S}\right]_{\max }} \\
\left(10^{15} \text { molecule } \mathrm{cm}^{-3}\right)\end{array}$ & $\begin{array}{l}{[\mathrm{HS}]_{\max , 0}} \\
\left(10^{12} \text { molecule } \mathrm{cm}^{-3}\right)\end{array}$ & $\begin{array}{l}{\left[\mathrm{NH}_{3}\right]} \\
\left(10^{14} \text { molecule } \mathrm{cm}^{-3}\right)\end{array}$ & $\begin{array}{l}{\left[\mathrm{NH}_{2}\right]_{0}} \\
\left(10^{12} \text { molecule } \mathrm{cm}^{-3}\right)\end{array}$ & $\begin{array}{l}k_{1} \pm \sigma \\
\left(10^{-13} \mathrm{~cm}^{3} \text { molecule }{ }^{-1} \mathrm{~s}^{-1}\right)\end{array}$ \\
\hline 294 & 2.0 & 0.1 & 27 & $8.15 \pm 0.33$ & 5.0 & 11.80 & 0.6 & $4.28 \pm 0.19^{a}$ \\
\hline 294 & 1.6 & 0.2 & 14 & $4.62 \pm 0.18$ & 5.7 & 5.30 & 0.5 & $4.05 \pm 0.21^{\mathrm{a}}$ \\
\hline 294 & 1.6 & 0.5 & 14 & $3.45 \pm 0.14$ & 10.6 & 5.40 & 1.3 & $4.11 \pm 0.18^{\mathrm{a}}$ \\
\hline 295 & 2.1 & 0.4 & 28 & $2.46 \pm 0.10$ & 6.1 & 7.90 & 1.5 & $4.21 \pm 0.22^{\mathrm{a}}$ \\
\hline 295 & 1.3 & 0.1 & 11 & $3.16 \pm 0.13$ & 2.0 & 5.10 & 0.3 & $4.39 \pm 0.13^{\mathrm{a}}$ \\
\hline 396 & 1.4 & 0.4 & 25 & $2.26 \pm 0.09$ & 5.6 & 7.26 & 1.4 & $4.15 \pm 0.20^{\mathrm{a}}$ \\
\hline 526 & 0.8 & 0.4 & 12 & $2.14 \pm 0.09$ & 5.3 & 11.10 & 2.2 & $4.42 \pm 0.15^{\mathrm{a}}$ \\
\hline 611 & 0.6 & 0.4 & 11 & $3.24 \pm 0.13$ & 8.0 & 7.21 & 1.4 & $4.55 \pm 0.25^{\mathrm{a}}$ \\
\hline 611 & 0.9 & 0.2 & 25 & $2.62 \pm 0.10$ & 3.2 & 10.80 & 1.1 & $4.20 \pm 0.22^{\mathrm{a}}$ \\
\hline 615 & 0.9 & 0.8 & 16 & $3.25 \pm 0.13$ & 16.0 & 5.10 & 2.0 & $4.32 \pm 0.19^{a}$ \\
\hline 802 & 0.4 & 0.5 & 9 & $1.73 \pm 0.07$ & 5.4 & 4.40 & 1.1 & $4.41 \pm 0.28^{a}$ \\
\hline 820 & 0.4 & 0.4 & 9 & $1.63 \pm 0.07$ & 4.0 & 4.30 & 0.8 & $4.48 \pm 0.31^{\mathrm{a}}$ \\
\hline 294 & 0.8 & 0.4 & 12 & $0.64 \pm 0.03$ & 1.6 & 4.59 & 0.9 & $137 \pm 8^{\mathrm{b}}$ \\
\hline 294 & 0.8 & 0.8 & 12 & $0.86 \pm 0.03$ & 4.3 & 4.65 & 1.8 & $130 \pm 10^{b}$ \\
\hline 415 & 0.6 & 0.5 & 12 & $0.33 \pm 0.01$ & 1.0 & 5.71 & 1.4 & $153 \pm 12^{b}$ \\
\hline 512 & 0.5 & 0.4 & 12 & $0.27 \pm 0.01$ & 0.7 & 6.52 & 1.3 & $166 \pm 15^{b}$ \\
\hline 513 & 0.5 & 0.8 & 12 & $0.19 \pm 0.01$ & 1.0 & 5.55 & 2.2 & $159 \pm 11^{b}$ \\
\hline
\end{tabular}

a $v=0$.

b $v=1$.

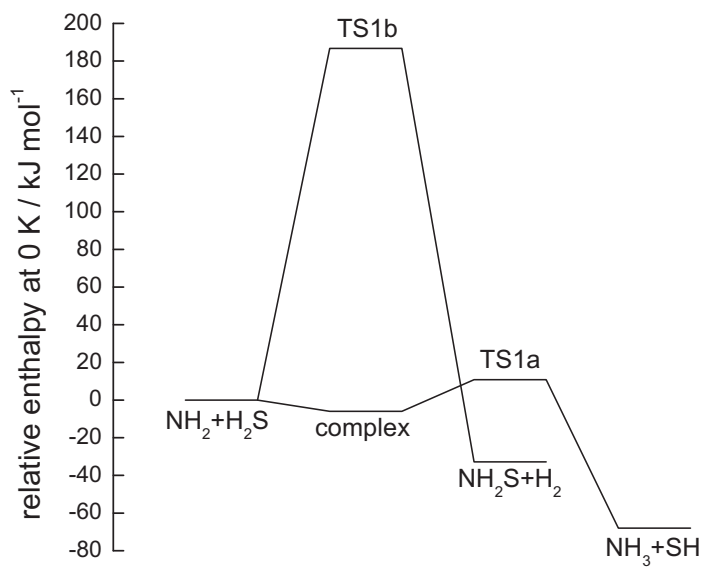

Figure 3. Potential energy diagram for $\mathrm{NH}_{2}+\mathrm{H}_{2} \mathrm{~S}$ derived via W1Usc theory.

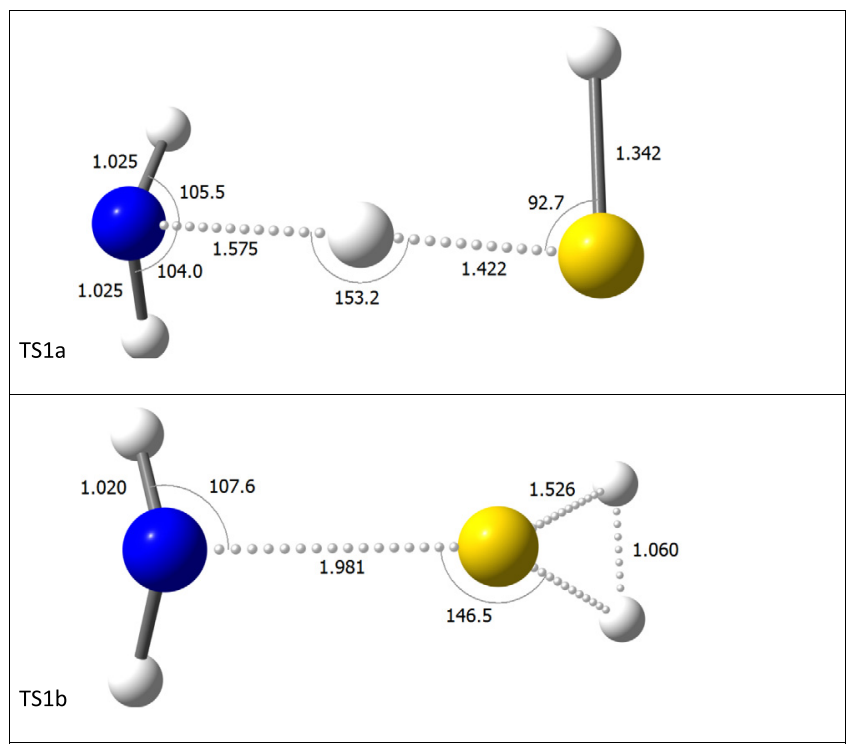

Figure 4. Structures for transition states computed at the $\mathrm{B} 3 \mathrm{LYP} / \mathrm{cc}-\mathrm{pV}(\mathrm{T}+\mathrm{d}) \mathrm{Z}$ level of theory. TS1a is for $\mathrm{NH}_{2}+\mathrm{H}_{2} \mathrm{~S} \rightarrow \mathrm{NH}_{3}+\mathrm{SH}$ and TS1b is for $\mathrm{NH}_{2}+\mathrm{H}_{2} \mathrm{~S} \rightarrow \mathrm{H}_{2} \mathrm{NS}+\mathrm{H}_{2}$. Distances are in $10^{-10} \mathrm{~m}$ and angles are in degrees. channel, where the reactants are hydrogen-bonded with an $\mathrm{N}-\mathrm{H}$ distance of $2.29 \times 10^{-10} \mathrm{~m}$ and are stabilized by $6 \mathrm{~kJ} \mathrm{~mol}^{-1}$. This is followed by a TS for $\mathrm{H}$-atom transfer from $\mathrm{S}$ to $\mathrm{N}$ where the $\mathrm{N}-\mathrm{H}$ distance has shortened to $1.58 \times 10^{-10} \mathrm{~m}$ (see Figure 4 ).

Initial density functional $(\mathrm{B} 3 \mathrm{LYP} / \mathrm{cc}-\mathrm{pV}(\mathrm{T}+\mathrm{d}) \mathrm{Z})$ results indicated that this abstraction TS had an energy (including zero point energy) $1.6 \mathrm{~kJ} \mathrm{~mol}^{-1}$ below the reactants. This would be a scheme of type IV as classified by Golden [16], which is capable of yielding a small or negative temperature dependence. The removal rate constant of vibrationally-excited $\mathrm{NH}_{2}$ of $1.5 \times 10^{-11} \mathrm{~cm}^{3}$ molecule ${ }^{-1} \mathrm{~s}^{-1}$ provides a possible measure of the rate of formation of entrance complexes. To be consistent with the observations, around one in 30 of these reactive collisions must lead to dissociation of the bound complex to $\mathrm{SH}+\mathrm{NH}_{3}$, with the rest leading back to the reactants. The complex itself is insufficiently stable to be a significant sink for $\mathrm{NH}_{2}$. We recognize that because the complexes are weakly bound they may not all survive long enough for every vibrationally-excited $\mathrm{NH}_{2}$ to lose energy via IVR, in which case the true capture rate constant would be higher than $1.5 \times 10^{-11}$ $\mathrm{cm}^{3}$ molecule $\mathrm{s}^{-1} \mathrm{~s}^{-1}$. Because the transition state for dissociation of the complex to $\mathrm{H}_{2} \mathrm{~S}+\mathrm{NH}_{2}$ is loose, with a high entropy, it is feasible for this dissociation to be faster than reaction of the complex via the tight transition state leading to final products, even though it has a lower energy.

However, our more accurate wavefunction-based (coupled cluster at the infinite basis set limit) results show this abstraction TS to lie $10.8 \mathrm{~kJ} \mathrm{~mol}^{-1}$ above the reactants, which makes the scheme of type I [16] and we may view the mechanism as

$\mathrm{NH}_{2}+\mathrm{H}_{2} \mathrm{~S} \underset{k_{-\mathrm{a}}}{\stackrel{k_{\mathrm{a}}}{\leftrightarrow}}$ complex $\stackrel{k_{\mathrm{b}}}{\rightarrow} \mathrm{NH}_{3}+\mathrm{SH}$

Assuming [complex] is in steady state, the effective bimolecular rate constant for $\mathrm{NH}_{2}$ removal is $k_{\mathrm{a}} k_{\mathrm{b}} /\left(k_{-\mathrm{a}}+k_{\mathrm{b}}\right)$. Using the 'Thermo' module of the Multiwell system [17,18] we have calculated the equilibrium constant $K_{\mathrm{c}}=k_{\mathrm{a}} / k_{-\mathrm{a}}$ to be approximately constant over $298-800 \mathrm{~K}$ at $\sim 2.5 \times 10^{-22} \mathrm{~cm}^{3}$ molecule ${ }^{-1}$, and the high-pressure limit for $k_{\mathrm{b}}$ to have $A=1.1 \times 10^{11} \mathrm{~s}^{-1}$ (which illustrates the tightness of this TS) with $E_{\mathrm{a}}=10.7 \mathrm{~kJ} \mathrm{~mol}^{-1}$. The Multiwell input file is provided in the Supplemental material, and it lists the rotational constants and frequencies and includes treatment of the lowest frequencies in the complex and the TS as hindered rotors and simple Eckart tunneling for $k_{\mathrm{b}}$. Initially we assumed the capture rate constant $k_{\mathrm{a}}$ to be equal to the $\mathrm{NH}_{2}(v=1)$ quenching rate constant, $\sim 1.5 \times 10^{-11} \mathrm{~cm}^{3}$ molecule ${ }^{-1} \mathrm{~s}^{-1}$. The model of Eq. (4) yields $k_{1}$ in 
agreement with experiment at $298 \mathrm{~K}$ but $k_{1}$ is more than an order of magnitude too high at $800 \mathrm{~K}$. Reducing the barrier for $k_{\mathrm{b}}$ lowers the temperature dependence of $k_{\mathrm{b}}$ and thus $k_{1}$, but makes its magnitude greater at the same time, so a compensating reduction in $k_{\mathrm{a}}$ is also required. A tolerable fit can be obtained by forcing $k_{\mathrm{a}}=5 \times 10^{-13} \mathrm{~cm}^{3}$ molecule $\mathrm{e}^{-1} \mathrm{~s}^{-1}$, a reduction by a factor of 30 , along with lowering the barrier at TS1a by $5 \mathrm{~kJ} \mathrm{~mol}^{-1}$. We regard these changes as large compared to the uncertainty in these quantities, and therefore consider this fit is unsatisfactory. We also comment that a more detailed RRKM analysis of the scheme in Eq. (4) which considers the energy dependence of $k_{-\mathrm{a}}$ and $k_{\mathrm{b}}$ yields similar results.

In the presence of a second molecule of $\mathrm{H}_{2} \mathrm{~S}$ the abstraction barrier is reduced by the requisite $5 \mathrm{~kJ} \mathrm{~mol}^{-1}$ at the CBS-QB3 level of theory, relative to $\mathrm{NH}_{2}+2 \mathrm{H}_{2} \mathrm{~S}$. This is equivalent to the reaction of $\mathrm{NH}_{2}$ with $\mathrm{H}_{2} \mathrm{~S}$ dimer, which is bound by $4 \mathrm{~kJ} \mathrm{~mol}^{-1}$ [19]. While giving an activation energy closer to that observed, this mechanism would yield a second-order dependence of the reaction rate on $\left[\mathrm{H}_{2} \mathrm{~S}\right]$ and therefore is rejected.

\section{Conclusion}

The first experiments on the $\mathrm{NH}_{2}+\mathrm{H}_{2} \mathrm{~S}$ system yield a rate constant that is both temperature-independent and small. While the exothermic products $\mathrm{NH}_{3}+\mathrm{H}_{2} \mathrm{~S}$ are plausible thermodynamically, we are not able to rationalize their formation quantitatively in terms of our existing potential energy diagram. We speculate that other pathways to these products, or possibly to $\mathrm{NH}_{2} \mathrm{~S}+\mathrm{H}_{2}$, remain to be elucidated.

\section{Acknowledgments}

We thank the National Science Foundation (Grant CBET-0756144) and the R.A. Welch Foundation (Grant B-1174) for support. Computational facilities were purchased in part with NSF Grant CHE-0741936.

\section{Appendix A. Supplementary data}

Supplementary data associated with this article can be found, in the online version, at http://dx.doi.org/10.1016/j.cplett.2014. 01.016.

\section{References}

[1] W. Nimmo, E. Hampartsoumian, B.M. Gibbs, Fuel 80 (2001) 887.

[2] P. Glarborg, Proc. Combust. Inst. 31 (2007) 77.

[3] B.A. Ellingson, D.G. Truhlar, J. Am. Chem. Soc. 129 (2007) 12765.

[4] I.W.M. Smith, J. Chem. Soc., Faraday Trans. 93 (1997) 3741.

[5] Y. Shi, P. Marshall, J. Phys. Chem. 95 (1991) 1654.

[6] L. Ding, P. Marshall, J. Phys. Chem. 96 (1992) 2197.

[7] G. Hancock, W. Lange, M. Lenzi, K.H. Welge, Chem. Phys. Lett. 33 (1975) 168.

[8] K. Yamasaki, A. Watanabe, A. Tanaka, M. Sato, I. Tokue, J. Phys. Chem. A 106 (2002) 6563.

[9] L. Ding, P. Marshall, J. Chem. Soc., Faraday Trans. 89 (1993) 419.

[10] S.P. Sander et al., Chemical Kinetics and Photochemical data for Use in Stratospheric Modeling, Evaluation Number 15, JPL Publication 06-2, JPL, Pasadena, 2006. <http://jpldataeval.jpl.nasa.gov>.

[11] E.C. Barnes, G.A. Petersson, J.J.A. Montgomery, M.J. Frisch, J.M.L. Martin, J. Chem. Theory Comput. 5 (2009) 2687.

[12] M.J. Frisch et al., Gaussian 09, Rev. C.01, Gaussian, Wallingford, CT, 2009.

[13] B. Ruscic, Active Thermochemical Tables (ATcT) values based on ver. 1.110 of the Thermochemical Network; <http://ATcT.anl.gov>, 2012 (accessed December 2013).

[14] R.C. Shiell, X.K. Hu, Q.J. Hu, J.W. Hepburn, J. Phys. Chem. A 104 (2000) 4339.

[15] P.S.S. Pereira, L.G.M. Macedo, A.S. Pimentel, J. Phys. Chem. A 114 (2010) 509.

[16] D.M. Golden, J. Phys. Chem. 83 (1979) 108.

[17] J.R. Barker et al., MultiWell-2013.1, University of Michigan, Ann Arbor, MI, 2013, <http://aoss-research.engin.umich.edu/multiwell/>.

[18] J.R. Barker, Int. J. Chem. Kinet. 33 (2001) 232.

[19] A. Bhattacherjee, Y. Matsuda, A. Fujii, S. Wategaonkar, ChemPhysChem 14 (2013) 905. 